\section{Evaluations and Correlated Responses for Resistance to Chloramben Herbicide in Cucumber}

\author{
Jack E. Staub ${ }^{1}$ and Larry D. Knerr ${ }^{2}$ \\ Vegetable Crops Research, U.S. Department of Agriculture, Agricultural \\ Research Service, Horticulture Department, University of Wisconsin, \\ Madison, WI 53706
}

\author{
Leslie A. Weston ${ }^{3}$ \\ Horticulture Department, University of Kentucky, Lexington, KY 40546
}

Additional index words. Cucumis sativus, recurrent selection, breeding

\begin{abstract}
The U.S. cucumber germplasm collection (753 accessions) and U.S. adapted processing cucumber (Cucumis sativus L.) inbreds and hybrids were surveyed for response to $6.7 \mathrm{~kg}$ ae/ha of chloramben. Nine plant introductions (PI 165952, 173892, 179676, 275411, 277741, 279464, 279465, 436609, and 482464) were classified as tolerant to chloramben, based on percentage and rate of field emergence and seedling vigor. All adapted strains evaluated were susceptible to chloramben injury. The chloramben-tolerant accessions $\left(C_{0}\right)$ were subjected to two cycles of recurrent half-sib family selection that resulted in $11 \mathrm{C}_{2}$ families. These families, a susceptible adapted line (WI 2870), and the resistant PI 436609 were evaluated in the field $(6.7 \mathrm{~kg}$ ae/ha) and laboratory $(0.0,0.01$, and $0.0001 \mathrm{M})$ for response to chloramben challenge. Significant $(P=0.05)$ differences between families were observed for percentage emergence and phytotoxicity ratings. Correlations between emergence and phytotoxicity ratings at two dates were low $\left(r^{2}=\mathbf{- 0 . 3 2}\right.$ and -0.05$)$. Significant $(P=0.05)$ interfamily differences were also recorded for percentage germination, hypocotyl length, primary root length, and number of lateral roots in the laboratory. Correlated responses between these growth variables were high $\left(r^{2}=0.78\right.$ to 0.84$)$, but correlations between field and laboratory observations were low $\left(r^{2}=-0.31\right.$ to 0.24$)$. We hypothesize that the genetic response to chloramben challenge under laboratory conditions depends on the concentration of the chemical administered. Chemical name used: 3-amino-2, 5-dichlorobenzoic acid (chloramben).
\end{abstract}

Inadequate weed control is a major factor that limits yield in commercial cucumber production. Average annual loss in value of the pickling cucumber crop in the United States due to weeds is estimated at $\$ 17,359,000$ (Weed Sci. Soc. Amer., 1984). Poor weed control is of particular concern in culture using once-over mechanical harvesting since weeds adversely affect the operation of mechanical harvesters, and high cucumber plant densities and rapid vine growth, which impede cultivation, render mechanical weed control impractical (Monaco and Miller, 1972; O'Sullivan, 1980).

Herbicides currently registered for cucumber production include bensulide, chloramben, DCPA, glyphosate, naptalam,

Received for publication 13 Aug. 1990. The authors thank Justin Cruz, USDA apprentice, for his invaluable help in performing the laboratory experiments. Mention of a trade name, proprietary product, or specific equipment does not constitute a guarantee or warranty by the USDA and does not imply its approval to the exclusion of other products that may be suitable. The cost of publishing this paper was defrayed in part by the payment of page charges. Under postal regulations, this paper therefore must be hereby marked $a d$ vertisement solely to indicate this fact.

'Research Horticulturist and Associate Professor. ${ }^{2}$ Former Graduate Research Assistant.

${ }^{3}$ Assistant Professor. paraquat, and trifluralin. Bensulide and naptalam often give poor annual weed control (Knerr and Hopen, 1989; Nell, 1977; Romanowski and Tanaka, 1965), while DCPA causes severe crop damage when surface-applied before crop emergence (Monaco and Miller, 1972). Trifluralin may result in crop injury and is limited to use in the southern United States (Weed Control Manual, 1986). Moreover, it cannot be applied until the threeto four-leaf stage of crop development, thereby requiring mechanical control of weeds until that time (Weed Control Manual, 1986). Glyphosate and paraquat are nonselective postemergence contact herbicides suitable only for use during seedbed preparation (Weed Control Manual, 1986). Chloramben is an excellent grass and broadleaf herbicide. However, cucumber tolerance to chloramben is marginal (Baker and Warren, 1962; Cole and Jordan, 1974; Knerr and Hopen, 1989), requiring the addition of activated charcoal over the seed row as a safening agent (Union Carbide Agr. Prod., 1989). Most growers are reluctant to use chloramben in this manner due to additional expenses and time inputs (S.F. Gorski, H.J. Hopen, T.J. Monaco, S. Weller, and B.H. Zandstra, personal communications). Furthermore, close plant spacings required for mechanical harvest make the use of activated charcoal impractical.

If commercially acceptable cucumber strains with resistance or tolerance to chloramben injury could be developed, then a production system that would incorporate more effective chemical and cultural practices for once-over mechanical harvest could be implemented. Cucumbers have been shown to possess low phenotypic variability for response to chloramben, most likely due to the effects of more than two genes (Miller et al., 1973). Germplasm sources for resistance to the methyl esterified form of chloramben (Miller et al., 1973) are no longer available. Therefore, a series of experiments were designed to: 1) identify sources of resistance to commercially available non-esterified form of chloramben (hereafter referred to as chloramben) when applied under field conditions; 2) develop a laboratory procedure that could evaluate germination response of seeds after being challenged with chloramben; and 3) determine whether a positive correlation exists between the laboratory germination procedure and field emergence and/or seedling performance.

An initial screening of the U.S. cucumber collection (753 accessions) and adapted inbred lines for tolerance to chloramben provided tolerant parents for a base population (cycle $1 ; \mathrm{C}_{1}$ ). This population was subjected to two cycles of half-sib recurrent selection for field tolerance to chloramben injury. The resulting $\mathrm{C}_{2}$ families and tolerant and resistant strains were used to determine whether a laboratory procedure would be correlated with field observations.

Identification of sources of tolerance and population development. Field experiments were conducted at the Univ. of Wisconsin Agricultural Research Station at Hancock on a Plainfield loamy sand (Typic Udipsamment; mixed mesic) in 1987 (screening) and 1989 (evaluation). In 1987, 25 seeds of each accession (753), and the U.S. Dept. of Agriculture processing cucumber inbred lines WI 1379, WI 1983, WI 2238, WI 2757, WI 2870, WI 3888, WI 3733, and SMR 18, GY14, 'Calypso', 'Clinton', 'Carolina', 'Expo', and 'Natsufuschinari' were sown in twentyfive $30-\mathrm{cm}$ rows (replications) on $1.5-\mathrm{m}$ centers that were arranged in a randomized complete-block design (RCBD). Chloramben (75DF) was surface-applied preemergence at $6.7 \mathrm{~kg}$ ae/ha (three times the recommended rate) to 20 replications ( 25 seeds per replication) with a tractor-mounted compressedair-powered sprayer that delivered 190 liters $\cdot h \mathrm{~h}^{-1}$. The remaining five replications were left untreated as a control for visual observations and were not used in the analysis. Twelve hours after herbicide application, plots were irrigated with $13 \mathrm{~mm}$ of water via overhead irrigation to move the herbicides into the seed zone. After 4 days, plots were irrigated three times weekly to ensure adequate moisture for germination and emergence.

Seedlings in treated plots were compared to those in control plots 1 and 3 weeks after emergence, and visually rated for chloramben injury on a five-point phytotoxicity scale [ 1 = no damage, 2 = slight injury (slight margin undulation or second leaf showing no 
Table 1. Response of plant characters (emergence, germination, and hypocotyl and root growth) of cucumber strains to chloramben during field and laboratory evaluation.

\begin{tabular}{|c|c|c|c|c|c|c|c|c|c|c|c|c|c|c|c|}
\hline \multirow{4}{*}{$\begin{array}{l}\text { Line, PI, } \\
\text { or family }\end{array}$} & \multirow{2}{*}{\multicolumn{3}{|c|}{$\begin{array}{c}\text { Field } \\
6.7 \mathrm{~kg} \text { ae/ha }\end{array}$}} & \multicolumn{12}{|c|}{ Laboratory } \\
\hline & & & & \multicolumn{4}{|c|}{$0.0 \mathrm{M}$} & \multicolumn{4}{|c|}{$10^{-5} \mathrm{M}$} & \multicolumn{4}{|c|}{$10^{-3} \mathrm{M}$} \\
\hline & \multirow{2}{*}{$\begin{array}{c}\text { Emergence } \\
(\%)\end{array}$} & \multicolumn{2}{|c|}{$\begin{array}{l}\text { Toxicity } \\
\text { rating }^{\mathbf{z}}\end{array}$} & \multirow{2}{*}{$\begin{array}{c}\text { Germ. } \\
(\%)\end{array}$} & \multicolumn{2}{|c|}{ Length $(\mathrm{mm})$} & \multirow{2}{*}{$\begin{array}{c}\text { Lateral } \\
\text { roots } \\
\text { (no.) }\end{array}$} & \multirow{2}{*}{$\underset{(\%)}{\text { Germ. }}$} & \multicolumn{2}{|c|}{ Length $(\mathrm{mm})$} & \multirow{2}{*}{$\begin{array}{c}\text { Lateral } \\
\text { roots } \\
\text { (no.) }\end{array}$} & \multirow{2}{*}{$\begin{array}{c}\text { Germ. } \\
(\%)\end{array}$} & \multicolumn{2}{|c|}{ Length (mm) } & \multirow{2}{*}{$\begin{array}{c}\text { Lateral } \\
\text { roots } \\
\text { (no.) }\end{array}$} \\
\hline & & 1 & 2 & & Hyp. & Root & & & Hyp. & Root & & & Hyp. & Root & \\
\hline 1 & 44 & 3.6 & 3.8 & 100 & 12.1 & 43.0 & 10.8 & 100 & 7.3 & 10.6 & 6.3 & 97 & 0 & 5.5 & 0 \\
\hline 2 & 57 & 3.5 & 3.9 & 100 & 12.5 & 45.5 & 10.5 & 100 & 6.8 & 8.1 & 6.0 & 100 & 0 & 6.1 & 0 \\
\hline 3 & 50 & 3.8 & 3.9 & 100 & 8.4 & 34.6 & 8.3 & 100 & 7.2 & 11.4 & 5.7 & 97 & 0 & 5.5 & 0 \\
\hline 4 & 62 & 3.5 & 3.8 & 100 & 5.6 & 32.9 & 7.6 & 100 & 4.2 & 10.8 & 3.4 & 100 & 0 & 4.8 & 0 \\
\hline 5 & 61 & 3.1 & 3.6 & 100 & 10.5 & 36.3 & 9.6 & 100 & 6.5 & 10.6 & 4.9 & 100 & 0 & 5.7 & 0 \\
\hline 6 & 38 & 3.5 & 4.0 & 96 & 6.5 & 34.8 & 7.0 & 100 & 5.3 & 9.8 & 3.4 & 69 & 0 & 4.1 & 0 \\
\hline 7 & 50 & 3.5 & 3.9 & 100 & 8.4 & 33.5 & 8.3 & 100 & 5.4 & 10.6 & 5.1 & 86 & 0 & 4.8 & 0 \\
\hline 8 & 48 & 3.4 & 3.8 & 100 & 8.1 & 26.9 & 8.0 & 97 & 6.6 & 11.7 & 6.9 & 86 & 0 & 5.7 & 0 \\
\hline 9 & 66 & 3.5 & 3.8 & 100 & 8.5 & 35.8 & 10.0 & 100 & 6.1 & 10.9 & 6.4 & 100 & 0 & 5.8 & 0 \\
\hline 10 & 60 & 3.0 & 3.5 & 96 & 8.4 & 34.1 & 9.5 & 93 & 4.6 & 14.6 & 6.9 & 100 & 0 & 5.6 & 0 \\
\hline 11 & 67 & 3.2 & 3.4 & 100 & 4.9 & 34.9 & 9.0 & 100 & 3.9 & 13.4 & 7.3 & 100 & 0 & 5.4 & 0 \\
\hline $436609 y$ & 48 & 3.6 & 3.7 & 96 & 8.6 & 34.8 & 6.7 & 95 & 6.2 & 10.2 & 8.4 & 96 & 0 & 5.6 & 0 \\
\hline WI $2870^{x}$ & 39 & 3.7 & 3.7 & 100 & 4.4 & 29.2 & 9.3 & 82 & 6.2 & 6.8 & 1.6 & 85 & 0 & 4.1 & 0 \\
\hline LSD $(0.05)$ & 17 & 0.5 & 0.4 & 5 & 2.2 & 7.6 & 2.7 & 9 & 2.7 & 4.5 & 2.4 & 17 & 0 & 1.4 & 0 \\
\hline
\end{tabular}

${ }^{2}$ Seedlings in treated plots were compared to those in control plots 1 (designated 1) and 3 (designated 2) weeks after emergence, and rated for chloramben injury on a 5-point visual phytotoxicity scale $[1=$ no damage, $2=$ slight injury (slight margin undulation or second leaf showing no damage), $3=$ moderate injury (margins of leaves undulating or deformed, cotyledons or first true leaves chlorotic), $4=$ severe injury (cotelydons fused, margins of first and/or second leaf undulating or deformed, cotyledons chlorotic, or seedlings without visible shoot apex), $5=$ seedling death or no emergence].

${ }^{y}$ Plant introduction tolerant to chloramben at $6.7 \mathrm{~kg}$ ae/ha under field conditions.

Inbred line susceptible to chloramben at $6.7 \mathrm{~kg}$ ae/ha under field conditions.

damage), 3 = moderate injury (margins of leaves undulating or deformed, cotyledons or first true leaves chlorotic), $4=$ severe injury (cotelydons fused, margins of first and/ or second leaf undulating or deformed, cotyledons chlorotic, or seedlings without visible shoot apex), 5 = seedling death or no emergence]. Mean phytotoxicity ratings were calculated for each accession and line after each evaluation.

Selection of tolerant plants was based on initial injury ( 1 week post-application) and whether plants recovered after being challenged ( 3 weeks post-application). Plants were selected that were rated 2 or lower after 1 week and recovered after 3 weeks (subsequent new leaves showing slight or no damage).

During initial field screening, PI 165952 (Turkey), PI 173892 (India; 'Khira'), PI 179676 (India; 'Kakri'), PI 275411 (Netherlands; 'Lange Groene Broei'), PI 277741 (Netherlands; 'Green Spot Super'), PI 279464 (Japan; 'Kara-Aonaga-Fushinari'), PI 279465 (Japan; 'Natsufushinari'), PI 436609 (Peoples Republic of China; 'Tsin Sanz Yen 15919'), and PI 482464 (Zambia) received a mean rating of 2.2 or lower (range $=1$ to 3 ) and, therefore, were designated as tolerant to chloramben challenge at $6.7 \mathrm{~kg}$ ae/ha. All other lines or hybrids tested received mean ratings of 4.2 (range $=3$ to 5 ) and were classified as susceptible.

Ten tolerant plants from each of these nine tolerant accessions were lifted from field plots and transplanted to a greenhouse where each plant was randomly hand pollinated using bulk pollen from four other tolerant plants to produce half-sib families $\left(C_{1}\right)$. Seeds from each fruit $\left(\mathrm{C}_{1}\right.$ half-sib family) were sown in 10 replications (25 seeds per replication), challenged with chloramben as described above, and 10 tolerant plants from the 11 highest ranking families were selected and randomly mated to produce a $\mathrm{C}_{2}$ half-sib population. Seeds of these families, WI 2870, and 'Calypso' were produced by controlled pollination under the same environmental conditions (greenhouse; June through Sept. 1988) and were used in the development of an in vitro procedure for determining chloramben toxicity.

Development of in vitro procedure. A series of experiments was designed to develop and evaluate a laboratory procedure for the detection of chloramben injury. To determine seed viability under optimum conditions, 10 seeds of the $\mathrm{C}_{2}$ selected families, the tolerant PI 436609 (phytotoxicity rating of 2.2) and the susceptible line WI 2870 (phytotoxicity rating of 4) were placed in 9$\mathrm{cm}$ petri plates on Whatman no. 1 filter paper moistened with $5 \mathrm{ml}$ of distilled water. Three replications of these families or lines were then arranged in a RCBD, placed in a controlled environment (27C and $85 \% \mathrm{RH}$ ), and rate and percentage of germination were recorded for 3 days.

A procedure for the detection of chloramben toxicity was developed by testing the response of seed of selected families and 'Calypso' to chloramben in a water and a gel medium. For this dose-response experiment, 100 seeds from four randomly selected halfsib families were bulked to supply a heterogeneous seed lot for testing. Chloramben (DF75) was diluted in either distilled water or a Gelrite (Scott Laboratories, Fiskeville, R.I. $) / \mathrm{MgCl}_{2}$ mixture $(0.4 \mathrm{~g}$ Gelrite per 0.04 $\mathrm{g} \mathrm{MgCl}_{2}$ in $100 \mathrm{ml}$ distilled water) to yield $0.1,0.01,0.001,0.0001$, and $0.00001 \mathrm{M}$ solutions. Chloramben in the Gelrite/ $\mathrm{MgCl}_{2}$ solution was dissolved by heating the mixture to a light boil. Three replicates of 25 seeds were placed in petri plates $(9 \mathrm{~cm})$ containing the various chloramben treatments in either $5 \mathrm{ml}$ of the water (control) or on 15 $\mathrm{ml}$ of the solidified Gelrite medium. Treatments were arranged in a RCBD and held at $27 \mathrm{C}$ and $85 \% \mathrm{RH}$ for 5 days, during which time rate and percentage of germination and primary root and hypocotyl length were recorded daily. Seeds were considered germinated when radicles protruded $3 \mathrm{~mm}$, and root and hypocotyl measurements were taken from the emergence point to the apex of the organ.

Selected families and control strains germinated $100 \%$ after 3 days. When placed on media containing $0,0.0001$, or $0.00001 \mathrm{M}$ of chloramben, seeds of 'Calypso' and the heterogeneous bulk of the $\mathrm{C}_{2}$ families germinated $100 \%$. The 0.01 and 0.001 M chloramben treatments did not affect germination $(100 \%)$, but did adversely affect primary root and hypocotyl length. Seed placed in $0.1 \mathrm{M}$ chloramben did not germinate.

The mean hypocotyl length of germinated 'Calypso' seeds $(45.3 \mathrm{~mm})$ was not significantly $(P=0.05)$ higher than bulked individuals $(41.7 \mathrm{~mm})$. The mean primary root and hypocotyl lengths of germinated seed of bulked families and 'Calypso' grown on 0.01 and $0.001 \mathrm{~m}$ chloramben were significantly less than those grown on the other concentrations examined, but were not different from each other. The mean root length of ' $\mathrm{Ca}$ lypso' germinated on 0.01 and $0.001 \mathrm{M}$ chloramben was 6.2 and $6.9 \mathrm{~mm}$, respectively, while root length of bulked families was 7.4 and $7.6 \mathrm{~mm}$, respectively. The mean hypocotyl length of germinated 'Calypso' seed grown on 0.01 and $0.001 \mathrm{M}$ chloramben was $0.1 \mathrm{~mm}$ and $7.0 \mathrm{~mm}$, respectively, and hypocotyl length of the bulked families was 0.0 $\mathrm{mm}$ and $9.1 \mathrm{~mm}$, respectively.

Correlation between laboratory and field. Based on results from the above experiments, and the few half-sib family seed 
Table 2. Correlations between field and laboratory response of 11 chloramben-tolerant cucumber families to chloramben $\left(6.7 \mathrm{~kg}\right.$ ae/ha and $10^{-5} \mathrm{M}$, respectively).

\begin{tabular}{lccc}
\hline \hline & \multicolumn{2}{c}{ Field } \\
\cline { 2 - 4 } & $\begin{array}{c}\text { Emergence } \\
\text { Laboratory }\end{array}$ & \multicolumn{2}{c}{ Phytotoxicity $^{z}$} \\
\hline Germination (\%) & 0.062 & 0.034 & 2 \\
Hypocotyl length & 0.193 & 0.063 & -0.047 \\
Root length & 0.188 & $-0.277^{*}$ & $0.244^{*}$ \\
Lateral roots (no.) & -0.110 & 0.113 & $-0.305^{* *}$ \\
\hline
\end{tabular}

${ }^{2}$ Seedlings in treated plots were compared to those in control plots 1 (1) and 3 (2) weeks after emergence, and rated for chloramben injury on a 5 -point visual phytotoxicity scale $[1=$ no damage, $2=$ slight injury (slight margin undulation or second leaf showing no damage), 3 = moderate injury (margins of leaves undulating or deformed, cotyledons or first true leaves chlorotic), $4=$ severe injury (cotelydons fused, margins of first and/or second leaf undulating or deformed, cotyledons chlorotic, or seedlings without visible shoot apex), $5=$ seedling death or no emergence.

Significant at $P=0.05$ or 0.01 , respectively.

available, 0, 0.01, and $0.0001 \mathrm{M}$ chloramben were chosen for evaluating correlated responses between field and laboratory tests. Seeds of the $11 \mathrm{C}_{2}$ families, PI 436609, and WI 2870 (designated as susceptible) were challenged by chloramben under field conditions $(6.72 \mathrm{~kg} \mathrm{ae} / \mathrm{ha})$ and in the laboratory using the Gelrite medium procedure. The Gelrite medium was chosen to ensure that chloramben would be evenly distributed and to prevent changes in concentration due to evaporation. WI 2870 was chosen for the bioassay because of its greater sensitivity than 'Calypso' (initial field screening and unpublished data).

In the field, 25 seeds of each $\mathrm{C}_{2}$ family seed lot were sown in 60-cm-long plots arranged in a RCBD with eight replications. Chloramben was applied as previously discussed, and percentage emergence and phytotoxicity ratings were taken 7 and 14 days after planting. Laboratory treatments, consisting of 25 seeds in 9 -cm petri dishes, were replicated three times, arranged in a RCBD and held at $27 \mathrm{C}$ and $85 \% \mathrm{RH}$ for 10 days, at which time germination percentage, hypocotyl, primary root length, and number of lateral roots were recorded.

Although the percent emergence of selected families $2,4,5,9,10,11$ was significantly higher than the susceptible control (WI 2870), only seed of families 9 and 11 emerged more rapidly than the tolerant control (PI 436609; Table 1). Mean phytotoxicity ratings 1 week after emergence of families 5 and 10 were significantly lower than for PI 436609, and ratings of families 5,10 , and 11 were significantly lower than for WI 2870. Differences among families were also detected. Seedlings of family 10 were significantly more tolerant to chloramben than those of families $1,2,3,4,6,7$, and 9 at 1 week. However, no differences were detected among cucumber populations 3 weeks after chloramben application.

Under laboratory conditions, no differences in germination percentage were detected among the strains examined when grown on medium without chloramben. Although the mean hypocotyl lengths of all families except 4 and 6 were significantly larger than those of the susceptible control, only the hypocotyls of families 1 and 2 were, on the average, significantly longer than those of the tolerant control PI 436609. The mean length of the primary root of families 1 and 2 was significantly longer than either control strain. Germinated seeds of families $1,2,5$, 9 , and 10 produced significantly more lateral roots than the tolerant control, but the mean number of roots was not significantly larger than that produced by the susceptible control.

The mean germination percentage of selected families and PI 436609 incubated on $0.0001 \mathrm{M}$ chloramben was significantly higher than for WI 2870 (Table 1). The mean hypocotyl elongation of seedlings of family 11 was lower than those of families $1,2,3$, and 7 grown in $0.0001 \mathrm{~m}$ chloramben. Similarly, the mean primary root length of WI 2870 was significantly less than those of families $3,8,10$, and 11 . The mean primary root length of PI 436609 was similar to all selected families. While the number of lateral roots recorded for WI 2870 was significantly less than for all families except 4 and 6 , lateral roots of families $2,3,4,5,6$, and 7 were shorter than those of PI 436609, which was similar to those of other selected families.

The radicles and cotyledons of seeds germinated on medium containing $0.01 \mathrm{M}$ chloramben emerged, but hypocotyls did not elongate and lateral roots were not produced (Table 1). Germination percentage was relatively high (85\% to $100 \%)$ among all families or lines tested, except for family $6(69 \%)$, for which it was significantly lower than for all other families except 7 and 8 and WI 2870. Mean primary root length of WI 2870 was significantly less than that for PI 436609 and families 2, 5, 8, 9, 10, and 12. Primary roots of family 2 were, on the average, significantly longer than those of family 6 , which was similar to WI 2870.

Data from selected families germinated on medium containing $0.0001 \mathrm{~m}$ chloramben were used to calculate correlated responses between and among characteristics recorded in the field and laboratory. Although correlations between percentage emergence (PE) and phytotoxicity ratings (PR-1 and PR-2) were low $(-0.32 \mathrm{PE} \times \mathrm{PR}-1,-0.05 \mathrm{PE}$ $\times$ PR-2, + 0.37 PR-1 $\times$ PR-2), correlations among some characteristics in the laboratory were relatively high. Hypocotyl length was highly correlated with root length
$(+0.79)$ and number of lateral roots $(+0.84)$, while root length and number of lateral roots were significantly correlated $(+0.81$; all correlations were significant at $P=0.05$ ).

If a laboratory screening procedure could be developed for the detection of plants tolerant to chloramben injury under field conditions, then selection for chloramben tolerance could be conducted in the laboratory. Laboratory selection would decrease costs and time required for the development of chloramben-tolerant germplasm. Correlated responses between field and laboratory data were low (Table 2). The lack of significant positive correlations between the data from the field and laboratory indicates that either these characters do not measure similar responses, or that perhaps herbicide challenge (particularly in the field) was not severe enough to provide identification of genotypic differences when they do exist.

The fact that the emergence of all strains tested was $>90 \%$ in untreated plots and emergence and early growth of seedlings were significantly affected by chloramben treatment indicates that the herbicide challenge in the field was measurable. It is known that soil moisture greatly affects chloramben activity (La Bonte and Hopen, 1985), and that immediate application of water after chloramben application increases toxicity (Knerr, 1987). In addition to controlled post-herbicide application of water to treated plots in this experiment, $\approx 5 \mathrm{~mm}$ of rainfall was received in 1989 within $24 \mathrm{~h}$ after chloramben treatment. It is possible that some of the herbicide was driven below the seed, thus reducing the effective quantity of the chemical around the seed during germination and emergence. This may explain the lack of differences among strains 3 weeks after emergence.

It is more likely that characteristics from the field and laboratory did not measure the same physiological response and that the germination environment can substantially modify the effects of the herbicide challenge. For example, although the mean emergence percentage of families 9 and 10 was similar in the field, the mean hypocotyl length (a potential measure of emergence) of family 9 was similar to PI 436609. When challenged in the laboratory with $0.0001 \mathrm{M}$ and $0.01 \mathrm{M}$ chloramben, no such differences were detected for these criteria.

The significantly high correlation between hypocotyl length, primary root length, and number of lateral roots suggests that one character provides indirect information about the other measured traits. Therefore, during laboratory evaluation of progeny for chloramben tolerance it would be appropriate to monitor germination percentage and just one of the other traits measured,

Chloramben inhibits root development (Weed Sci. Soc. Amer., 1989); also, metabolism in certain plants appears to result in the formation of conjugates rather than degradation products (Stoner and Wax, 1968). Our data confirm these earlier results regarding inhibition of root development. For instance, hypocotyl elongation of all strains 
tested at 0.0001 m chloramben was decreased when compared to growth on media without chloramben. Likewise, primary root length and the number of lateral roots were significantly depressed with increasing concentrations of chloramben in the growing medium.

Differential response of cucumber strains was noted with increasing concentrations of chloramben. Mean primary root length of families 1 and 2 was significantly greater than of WI 2870 on medium without chloramben. At 0.0001 m chloramben, the primary root lengths of families 1 and 2 were similar to those of WI 2870. Since the potential effects of the growing environment, seed age, and seed handling procedures were eliminated in this experiment, this difference is probably due to genotype. The genetic response to chloramben challenge under laboratory conditions described here may depend on the concentration administered. The fact that the mean primary root length of family 2 individuals was significantly higher than that of WI 2870 individuals at $0.01 \mathrm{M}$ chloramben lends support to this hypothesis.

The physiological and biochemical processes that control germination and emergence in cucumber differ (Staub et al., 1986). The effect of chloramben on germination and primary root development appears to have a demonstrable genetic component. For instance, similar germination percentages were observed in family 8 and WI 2870 when grown on $0.01 \mathrm{M}$ chloramben, but the primary root extension of family 8 was significantly greater than WI 2870 . Likewise, the germination percentage of WI 2870 was higher $(P=0.10)$ than of family 6 , but their primary root extension was similar. The fact that, when challenged with $0.0001 \mathrm{M}$ chloramben, germination of family 4 individuals was $100 \%$ but their hypocotyl extension was not substantial lends support to this hypothesis.

Development of efficient field and laboratory herbicide screening procedures may allow for development of germplasm with significant levels of herbicide tolerance. Such germplasm would be an important component of integrated pest management programs to support low-input sustainable agriculture.

\section{Literature Cited}

Baker, R.S. and G.F. Warren. 1962. Selective herbicidal action of amiben on cucumber and squash. Weeds 10:219-224.

Cole, A.W. and T.N. Jordan. 1974. Seedling and yield response of cucumber to naptalam and chloramben. Weed Sci. 22:604-607.

Knerr, L.D. 1987. Naptalam as a safener for cucumber (Cucumis sativus L.) against the phytotoxic effects of chloramben. MS Thesis, Univ. of Wisconsin-Madison. p. 62-70.

Knerr, L.D. and H.J. Hopen. 1989. Naptalam as a safener against chloramben in cucumber $(\mathrm{Cu}$ cumis sativus L.). Weed Technol. 3:445-449.

La Bonte, D.R. and H.J. Hopen. 1985. Apparent safening of chloramben for cucumbers by combination with naptalam. Proc. N. Central Weed Control Conf. 40:41.

Miller, J.C., D. Penner, and L.R. Baker. 1973.
Basis of variability in the cucumber for resistance to chloramben methyl ester. Weed Sci. 21:207-211.

Monaco, T.J. and C.H. Miller. 1972. Herbicide activity in close-spaced, pickling cucumbers. Weed Sci. 20:545-548.

Nell, C.J. 1977. Weed control in cucumbers in a conventional planting and in a stale bed. Proc. Northeastern Weed Sci. Soc. 31:248-251.

O'Sullivan, J. 1980. Irrigation, spacing, and nitrogen effects on yield and quality of pickling cucumbers grown for mechanical harvesting. Can. J. Plant Sci. 60:923-928.

Romanowski, R.R. and J.S. Tanaka. 1965. An evaluation of herbicides for use with cucumber (Cucumis sativus) and watermelon (Citrullus vulgaris) in Hawaii. Hawaii Agr. Expt. Sta. Prog. Rpt. 144.

Staub, J.E., J. Nienhuis, and R.L. Lower. 1986.
Effects of seed preconditioning treatments on emergence of cucumber populations. HortScience 21:1356-1359.

Stoner, E.W. and L.M. Wax. 1968. Amiben metabolism and selectivity. Weed Sci. 16:283-288.

Union Carbide Agricultural Products. 1989. Union Carbide 1989 chemical guide. Research Triangle Park, N.C.

Weed Control Manual 1986 and Herbicide Guide. 1986. Ag. Consultant and Fieldman, a Meister Publ. p. 196-197.

Weed Science Society of America. 1984. Crop losses due to weeds in Canada and the United States. Weed Sci. Soc. Amer., Champaign, Ill. p. 1-22.

Weed Science Society of America. 1989. Herbicide handbook of the Weed Society of America. 6th ed. Weed Sci. Soc. Amer., Champaign, Ill. p. 51-52, 192-193. 